\title{
Automatic System for Failure Detection in Hydro-Power Generators
}

\author{
Luis Carlos Ribeiro', Levy Ely de Lacerda de Oliveira ${ }^{2,3}$, Erik Leandro Bonaldi'2,3, \\ Luiz Eduardo Borges da Silva3, Camila Paes Salomon ${ }^{2,3}$, Jonas G. Borges da Silva ${ }^{2,3}$, \\ Germano Lambert-Torres ${ }^{2}$ \\ ${ }^{1}$ Itapebi-Neoenergia Power Plant Co., Salvador, Brazil \\ ${ }^{2}$ Institute Gnarus, Itajuba, Brazil \\ ${ }^{3}$ Itajuba Federal University, Itajuba, Brazil \\ Email: Iribeiro@neoenergia.com, gnarus@institutognarus.com.br, leborges@unifei.edu.br
}

Received December 2013

\section{Abstract}

This paper presents an automatic system for failure detection in hydro-power generators. The main idea of this system is to detect failure using current and voltage signals acquired without any type of internal interference in the generator operation. The detected failures could be mechanical or electrical origins, such as: problems in bearings, unwanted vibrations, partial discharges, misalignment, unbalancing, among others. It is possible because the generator acts as a transducer for mechanical problems, and they appear in current and voltage signals. This automatic system based on electric signature analysis has been installed in Itapebi Power Plant generators since 2012. Some results are presented in this paper.

\section{Keywords}

Automatic System; On-Line Measurements; Digital Signal Processing; Predictive Maintenance; Failure Detection

\section{Introduction}

Different from the countries in the world, the main part of power generator in Brazil is made by hydraulic sources of primary energy. More than $85 \%$ of the energy in our country is provided from hundreds of small power plant, around $5 \mathrm{MW}$, until very large power plants, such Itaipu (14 GW) and Tucurui (8.4 GW). This tendency is increasing each time more, with the new power plant in Belo Monte (11.2 GW, under construction) and Tapajos (8.4 GW).

The hydro-power generator has a different construction of the turbo-generators. Usually, hydro-generators have their construction made with vertical axis, they are larger than tall (it means, the axis is small and the diameter is bigger), and internally they are salient pole machine and have a speed 10 times smaller than the turbo-generators. Also, the operation machine in the system and the controls are completely different [1]. With all these specific features, the signatures of the failures are different from hydro-generators and turbo-generators [2].

How to cite this paper: Ribeiro, L.C., de Oliveira, L.E. de L., Bonaldi, E.L., da Silva, L.E.B., Salomon, C.P., da Silva, J.G.B. and Lambert-Torres, G. (2014) Automatic System for Failure Detection in Hydro-Power Generators. Journal of Power and Energy Engineering, 2, 36-46. http://dx.doi.org/10.4236/ipee.2014.24006 
This paper presents an automatic online system, based on signal processing, in special FFT and signature analysis, to infer premature failures in large hydro-power generator unit; it means this system is able to detect failures in electric part of the generator and mechanical failures in generator, coupling, turbine and bearings. It is possible because any mechanical problem interferes in magnetic field of the generator and appears in a change in current and voltage signals. The problem is that sometimes these changes are too small, under the noise of the signals [3].

This paper presents some results of the automatic system from the Itapebi Power Plant generator units. This system is installed since 2010 in unit \#3 and since 2012 in units \#1 and \#2.

\section{Brief Description of Installation at Itapebi Power Plant}

Itapebi Power Plant is a company of the Neoenergia Co., located between Minas Gerais and Bahia States, in Southeast part of Brazil. Its primary energy is supplied by Jequitinhonha River. Itapebi is an Indian name, and means "flattened stone water".

This power plant is composed by three Alstom generating units. Each one has $150 \mathrm{MW}$ with nominal voltage equal to $13.8 \mathrm{kV}$, nominal current equal to $6.693 .9 \mathrm{~A}$, and nominal speed equal to $138.5 \mathrm{rpm}$. The frequency in Brazil is $60 \mathrm{~Hz}$. Figure 1 shows the unit \#2.

The hardware of the automatic system is composed by three main parts: current transducers, voltage transducers, and data acquisition system. The transducers must be able to reproduce in its secondary all existing values of the primary part. It is important because sometimes the imperfections in signals have small values, in special during the initial part of the failures. The data acquisition system is a commercial product existing in the market. Figure 2 shows the hardware before the installation; while Figure 3 shows the hardware installed in the panel of unit \#2.

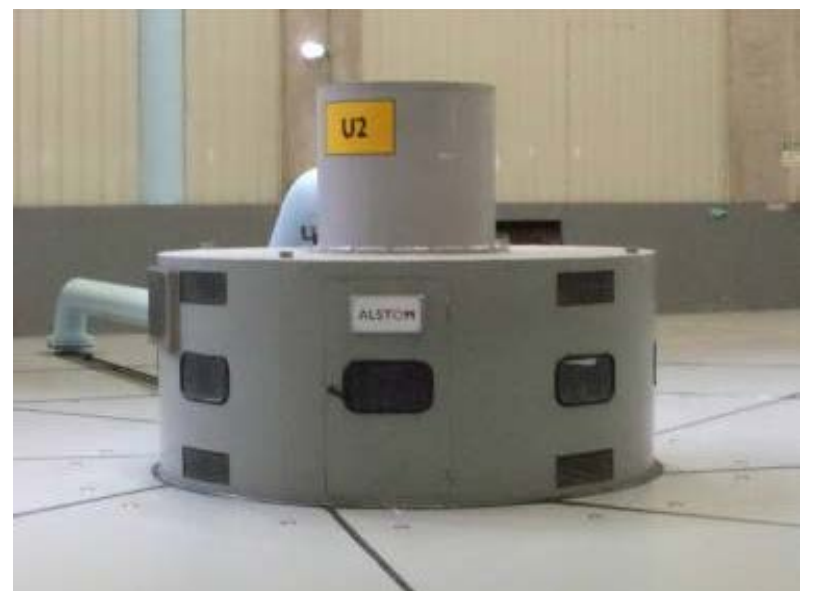

Figure 1. Picture of unit \#2 at Itapebi Power Plant.

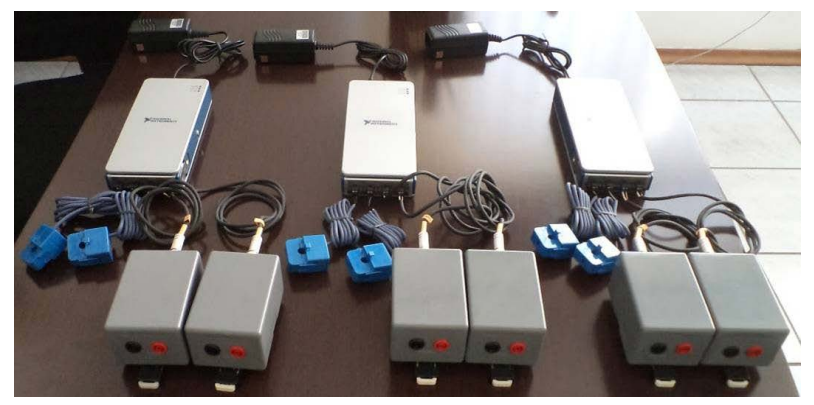

Figure 2. Hardware of the automatic system, composed by power supply (black boxes), data acquisition system (white boxes), current transducers (in blue), and voltage transducers (gray boxes). 


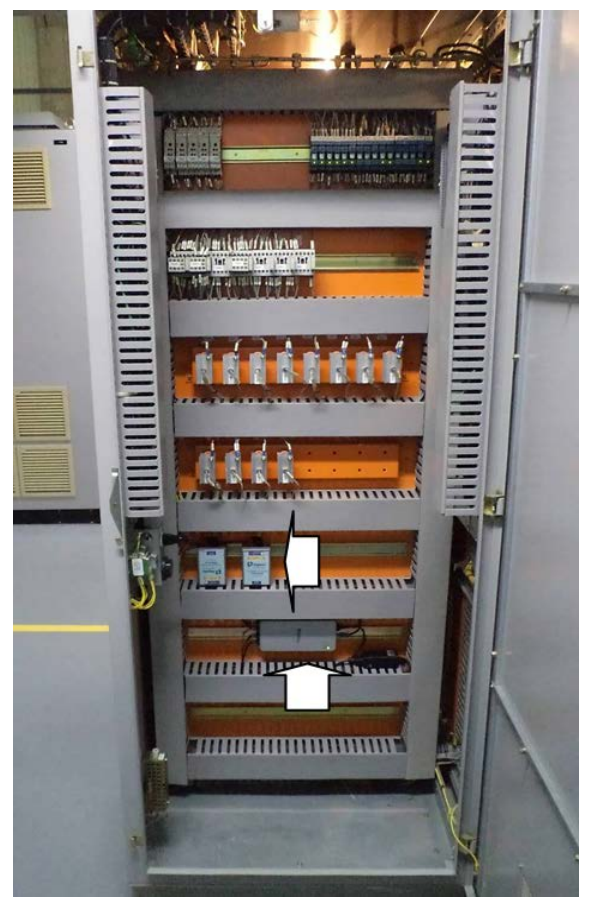

(a)

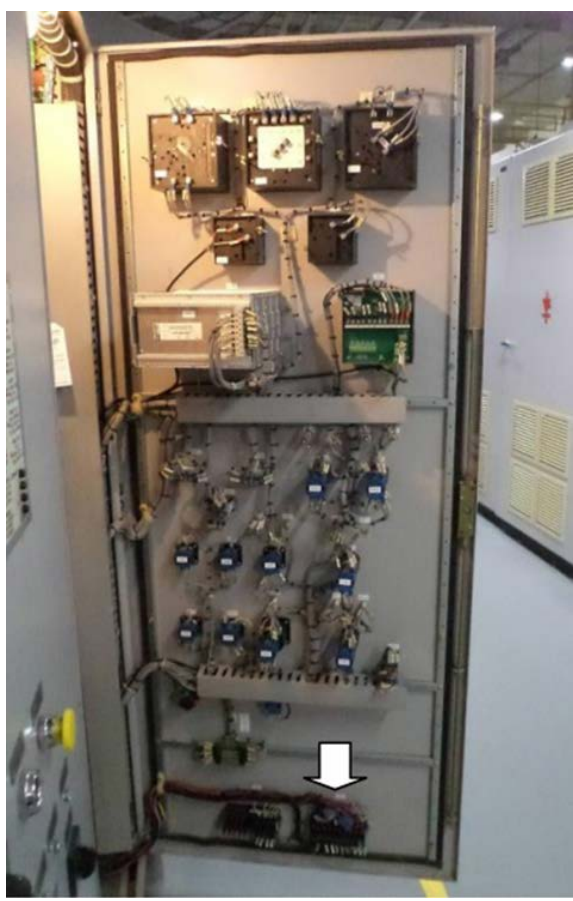

(b)

Figure 3. Installation in the panel of unit \#2: (a) Front view-voltage transducers and data acquisition system, and (b) Rear view-current transducers.

\section{Fundamentals of Automatic System for Failure Detection}

The main idea behind the automatic system is a comparison between the signatures of the healthy generator and defective generator. The healthy generator has a set of "nominal" frequencies, when a failure happens these frequencies are modified, in intensity and values. For example, when an air-gap rotor eccentricity starts in the generating unit; the intensity of one specific frequency increases. Figure 4 shows this example.

The comparison between the healthy signal and the actual signals is made using initially the Enhanced Park's Vector Approach (EPVA) technique [2]. This approach transforms the three-phase signals in two signals: direct signal and quadrature signal. And then, the Park's vector is computed. Mathematically, a healthy generator has the following signals for current:

$$
\begin{aligned}
& i_{A}=i_{M} \cos (\omega t-\alpha) \\
& i_{B}=i_{M} \cos \left(\omega t-\alpha-\frac{2 \pi}{3}\right) \\
& i_{C}=i_{M} \cos \left(\omega t-\alpha+\frac{2 \pi}{3}\right)
\end{aligned}
$$

where $i_{M}$ is the peak value of current signal; $\omega$ is the angular frequency in rad/s; $\alpha$ is the initial phase angle in rad; $t$ is the time variable; and, $i_{A}, i_{B}, i_{C}$ are respectively the currents in the phases $A, B$ and $C$.

Then the direct $\left(i_{D}\right)$ and quadrature $\left(i_{Q}\right)$ signals are:

$$
\begin{aligned}
& i_{D}=\left(\frac{\sqrt{6}}{2}\right) i_{M} \cos (\omega t-\alpha) \\
& i_{Q}=\left(\frac{\sqrt{6}}{2}\right) i_{M} \operatorname{sen}(\omega t-\alpha)
\end{aligned}
$$

For the healthy generator, the signals and the Park circle are presented in Figure 5. 


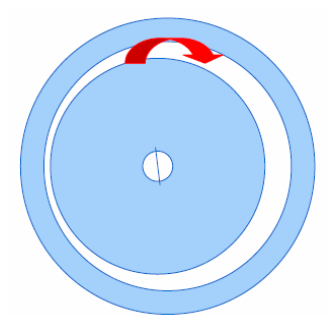

(a)

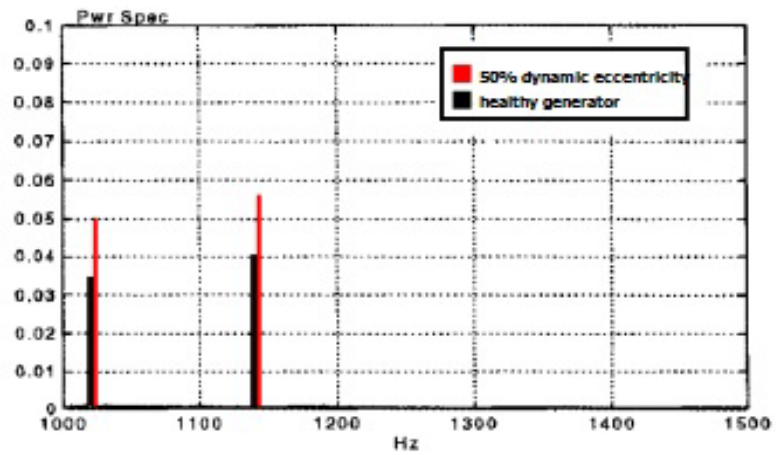

(b)

Figure 4. Example of eccentricity: (a) Air-gap rotor eccentricity, (b) Healthy generator (black signals) and generator with $50 \%$ dynamics eccentricity.

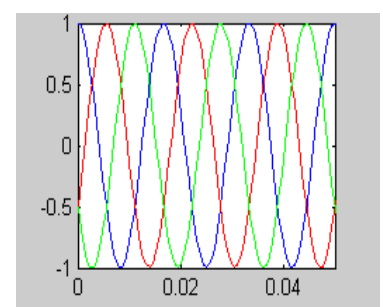

(a)

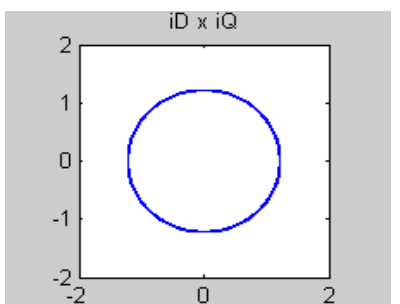

(b)

Figure 5. Healthy generator: (a) Actual signals, (b) Park circle.

When a problem appears in the generator, the current signals could change to:

$$
\begin{aligned}
& i_{A}=i_{d} \cos \left(\omega t-\alpha_{d}\right)+i_{i} \cos \left(\omega t-\beta_{i}\right) \\
& i_{B}=i_{d} \cos \left(\omega t-\alpha_{d}-\frac{2 \pi}{3}\right)+i_{i} \cos \left(\omega t-\beta_{i}+\frac{2 \pi}{3}\right) \\
& i_{C}=i_{d} \cos \left(\omega t-\alpha_{d}+\frac{2 \pi}{3}\right)+i_{i} \cos \left(\omega t-\beta_{i}-\frac{2 \pi}{3}\right)
\end{aligned}
$$

where $i_{d}$ is the maximum current value of direct sequence; $i_{i}$ is the maximum value of reverse sequence current; $\alpha_{d}$ is the initial phase angle of direct sequence current in rad; and $\beta_{i}$ is the initial phase angle reverse sequence current in rad.

Then the direct $\left(i_{D}\right)$ and quadrature $\left(i_{Q}\right)$ signals for this conditions are:

$$
\begin{aligned}
& i_{D}=\left(\frac{\sqrt{3}}{\sqrt{2}}\right)\left(i_{d} \cos \left(\omega t-\alpha_{d}\right)+i_{i} \cos \left(\omega t-\beta_{i}\right)\right) \\
& i_{Q}=\left(\frac{\sqrt{3}}{\sqrt{2}}\right)\left(i_{d} \operatorname{sen}\left(\omega t-\alpha_{d}\right)-i_{i} \operatorname{sen}\left(\omega t-\beta_{i}\right)\right)
\end{aligned}
$$


For this generator, the signals and the Park circle are presented in Figure 6.

And then, applying FFT [4] in this case, a new frequency appears, as shown in Figure 7. The problem now produced a relation between this frequency and the associated failure. Usually, the higher the frequency signal intensity the greater the intensity of the failure. Sometimes a defect could be also related to more than one type of frequency. However, in some specific cases, the decrease in the intensity of one existing frequency may also be associated with a failure.

In this way, the definition of each pattern is directly linked to the constructive aspects of the machine (such as number of poles, bearing type, etc.) as well as its operation characteristics (speed, nominal frequency, etc.). In general, the searched frequencies follow the expression:

$$
f=f_{1} \pm k \cdot f_{c}
$$

where, $f_{1}$ represents the fundamental frequency, $f_{c}$ is the failure frequency, $k$ is the integer number, and $f$, the final frequency existing in the spectrum.

There are three main types of searched frequencies, named demodulated, with modulation, and with a modulation under other modulation. The first type occurs when they appear in the spectrum directly, for instance, values of $f c$ equal to $30 \mathrm{~Hz}$ in a $60 \mathrm{~Hz}$ system. The second type, with modulation, the value of $f c$ is modulated under a fundamental frequency; and the third type, modulation under modulation, is obtain when the modulation is produced under a multiple of fundamental frequency. Figure 8 shows these three types of searched frequencies.

The automatic system has a user-interface, developed to operators, and shown in Figure $\mathbf{9}$ (the interface is written in Portuguese, the Brazilian native language). In this interface, it is possible to manage all features of the software, such as: visualized the measurement values (region 1 in Figure 9), last acquisitions (region 2), historic of the acquisitions (a tab in the bottom of the screen), and to get access to each type of analysis (region 3) with the following techniques: CSA, VSA, and EPVA. In the tabs "Parametros Eletricos" (Electric Parameters) and "Outros" (Others), the operator can introduced the generator data and the acquisition parameter control, respectively.

\section{Illustrative Results of the Automatic System}

In this section, some results obtained by the automatic system for failure detection in the unit \#2 at Itapebi Power Plant are presented.

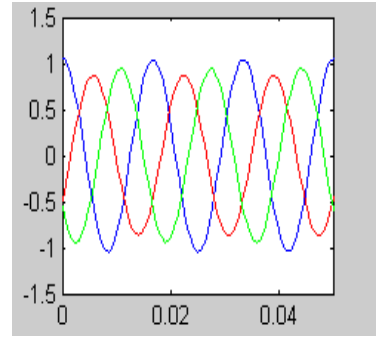

(a)

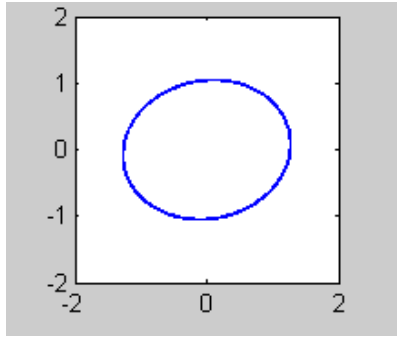

(b)

Figure 6. Actual generator: (a) Actual signals, (b) Park circle.

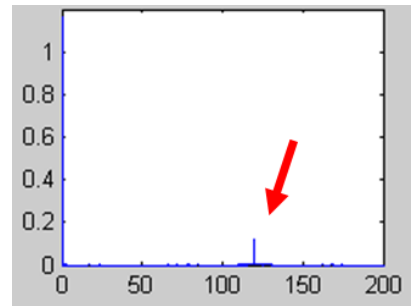

Figure 7. New frequency in this example the value is twice the fundamental frequency. 


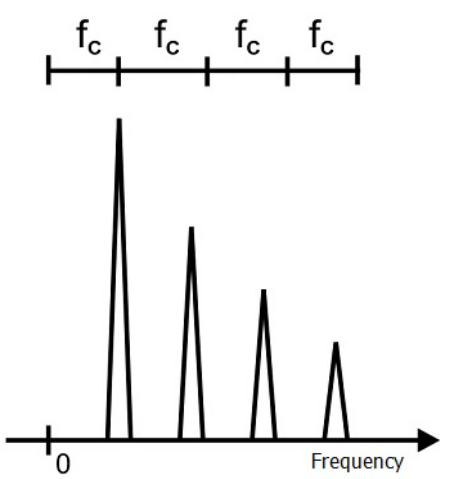

(a)

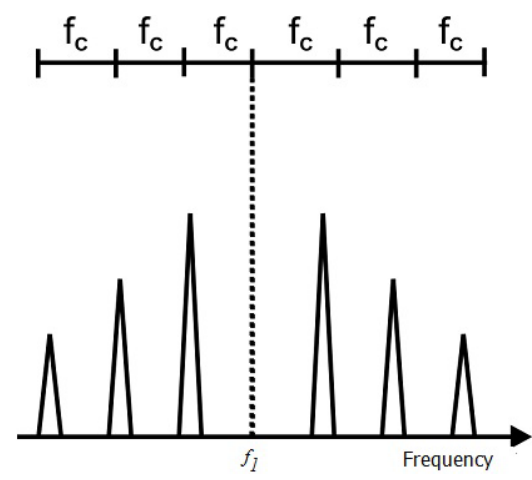

(b)

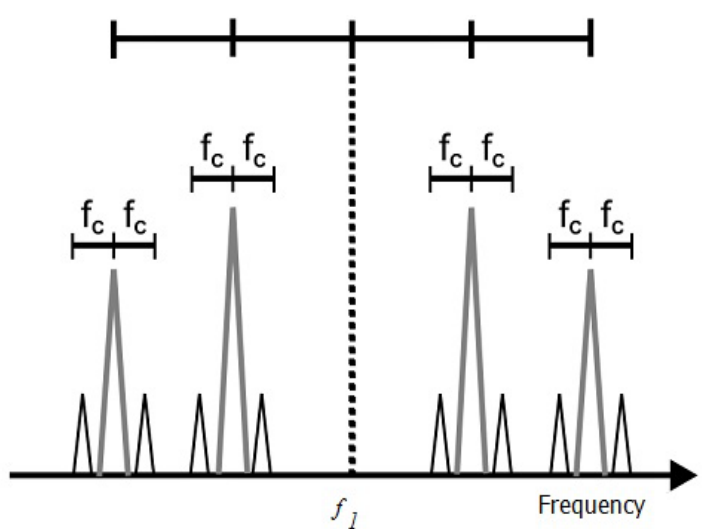

(c)

Figure 8. Searched frequencies: (a) Demodulated, (b) With modulation, and (c) With modulation under other modulation.

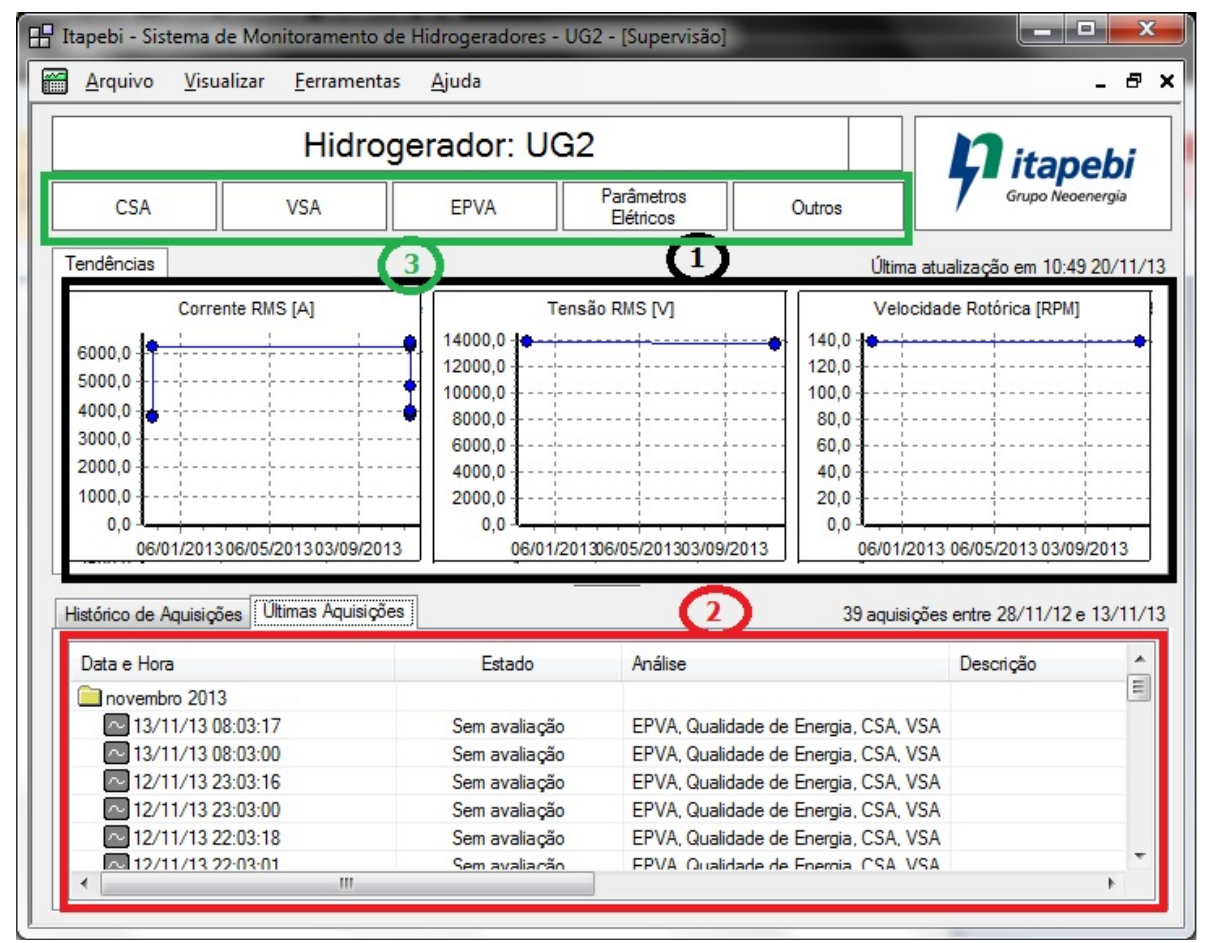

Figure 9. Main screen of the automatic system for failure detection, configured for unit \#2. 
For the analysis of trend curves of failure patterns, whose acquisitions have been the generator load was around $56 \%$ of the nominal load, in order to be viable a comparison between the most recent data and data collected. Figure 10 shows the RMS current trend curve in the phase of the generator in this range of chosen load.

Other important measurement values were the voltage electric imbalance, shown in Figure 11. This imbalance is around 0,04\% between phases. For educational purposes, Figure 12 shows the EPVA signatures of current and voltage, with emphasis on the indicative component of electrical stator imbalance and circle Park.

The THD of the voltage was around $0.97 \%$ to $0.95 \%$ for phase A, phase B and $1.03 \%$ for phase C (shown in Figure 13).

One of the patterns for short-circuit in stator winding is the rotational frequency, as shown in Figure 14, the signatures of current and voltage. Note that the rotation frequency components are immersed in the noise level

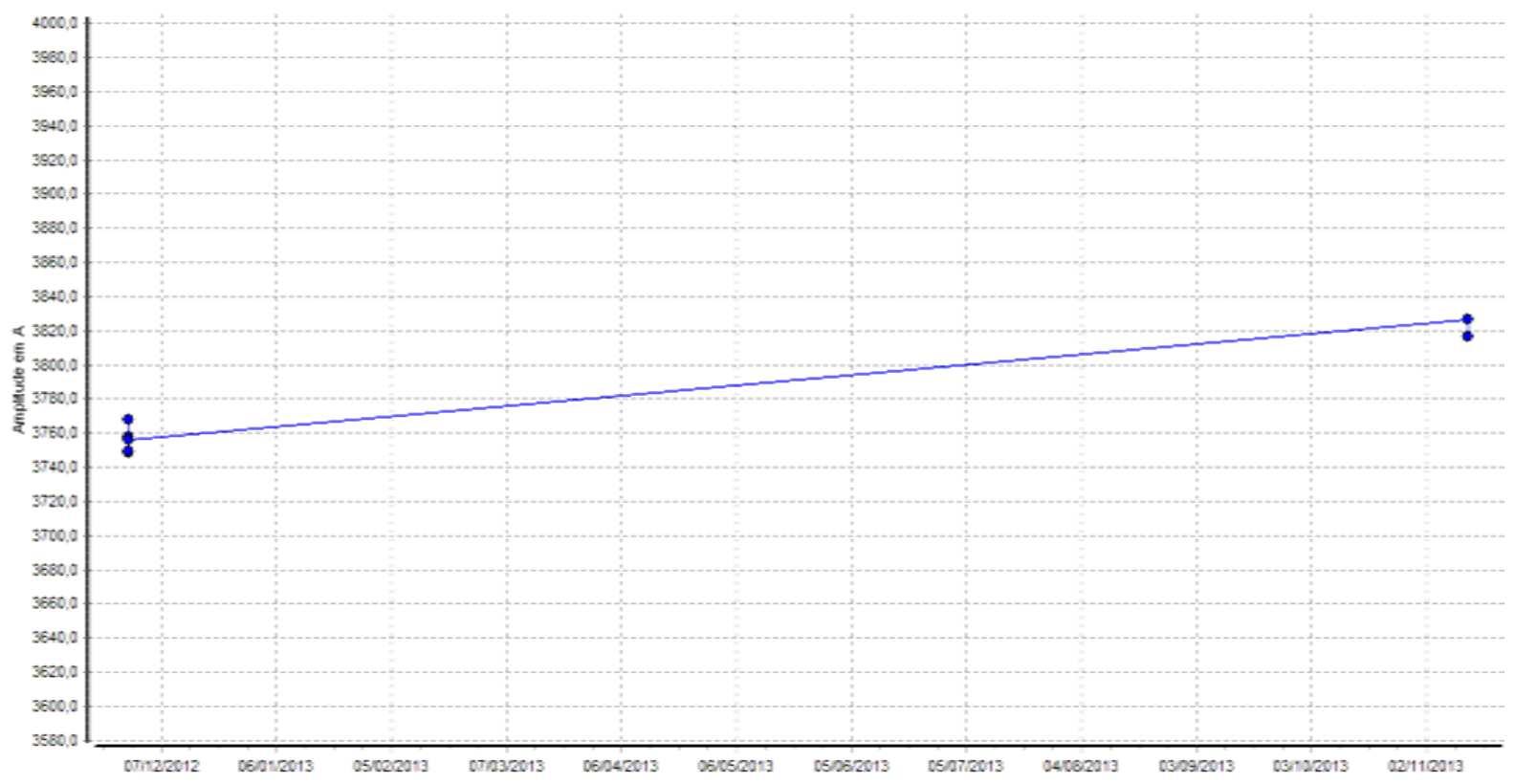

Figure 10. RMS values of the current on the phase A of the generator \#2 with $56 \%$ of the nominal load.

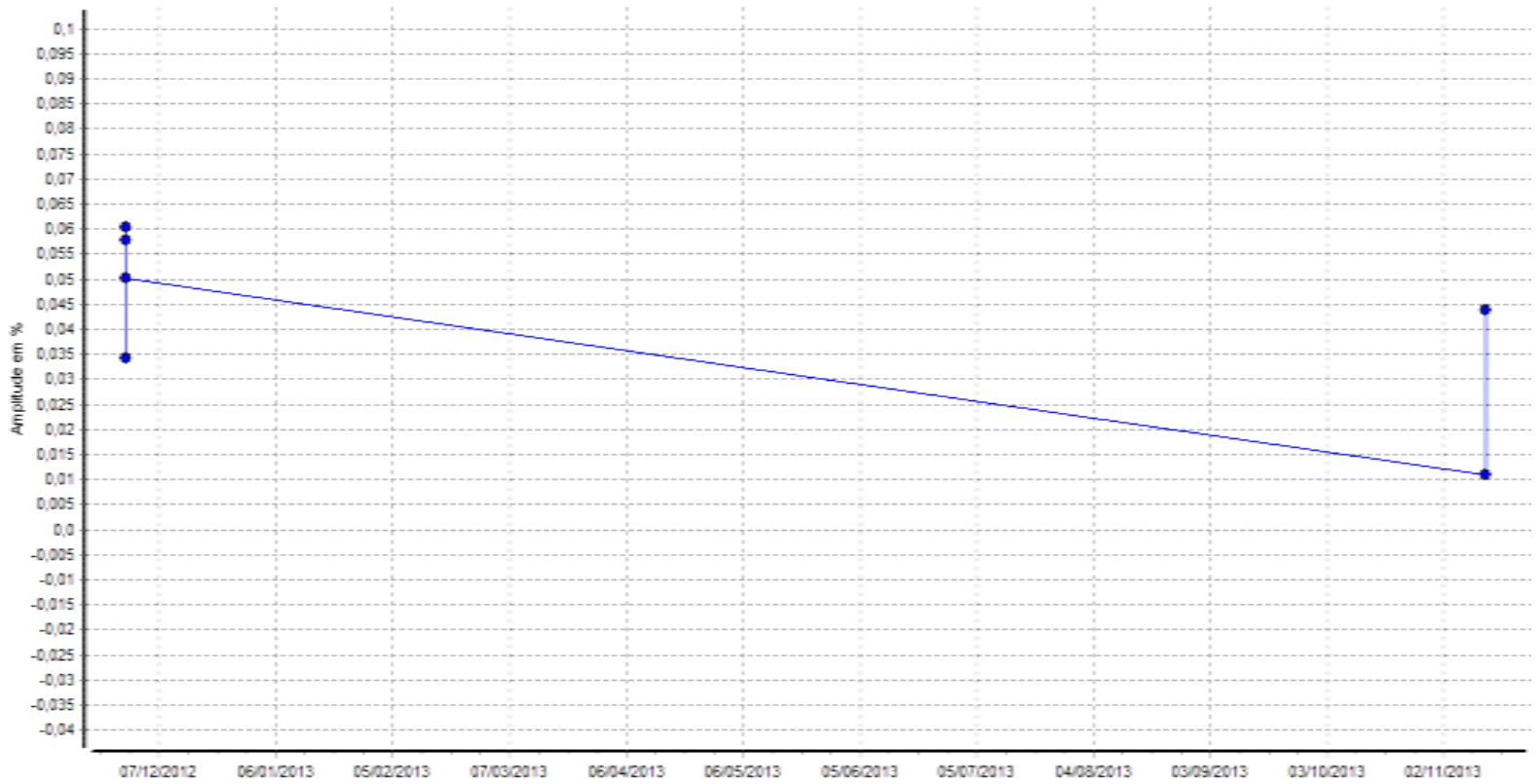

Figure 11. Voltage electric imbalance for unit \#2. 
Andise EPVA

Aquisiçăo: $121117131803-16$
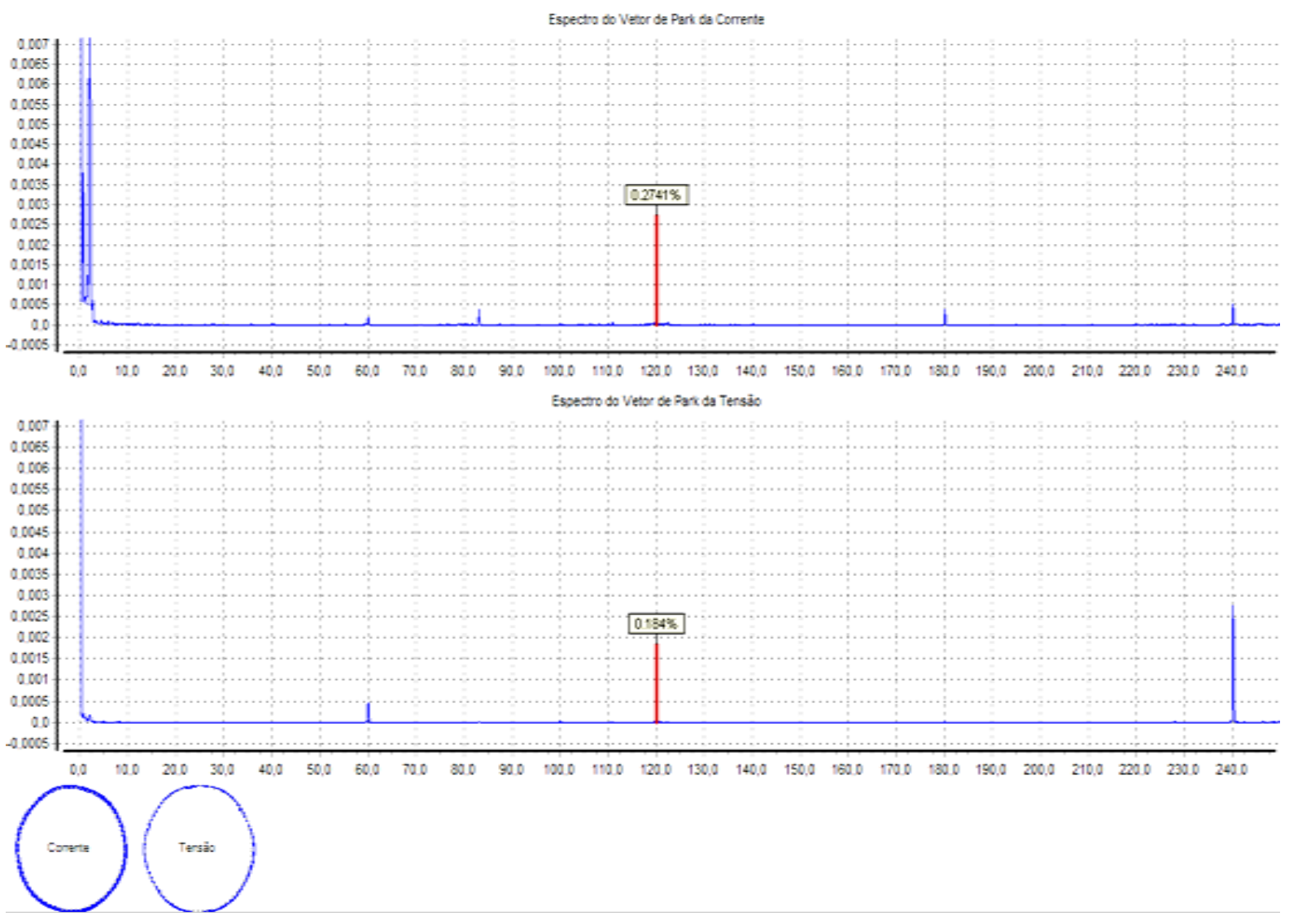

Figure 12. Voltage electric imbalance for unit \#2 treated by EPVA.

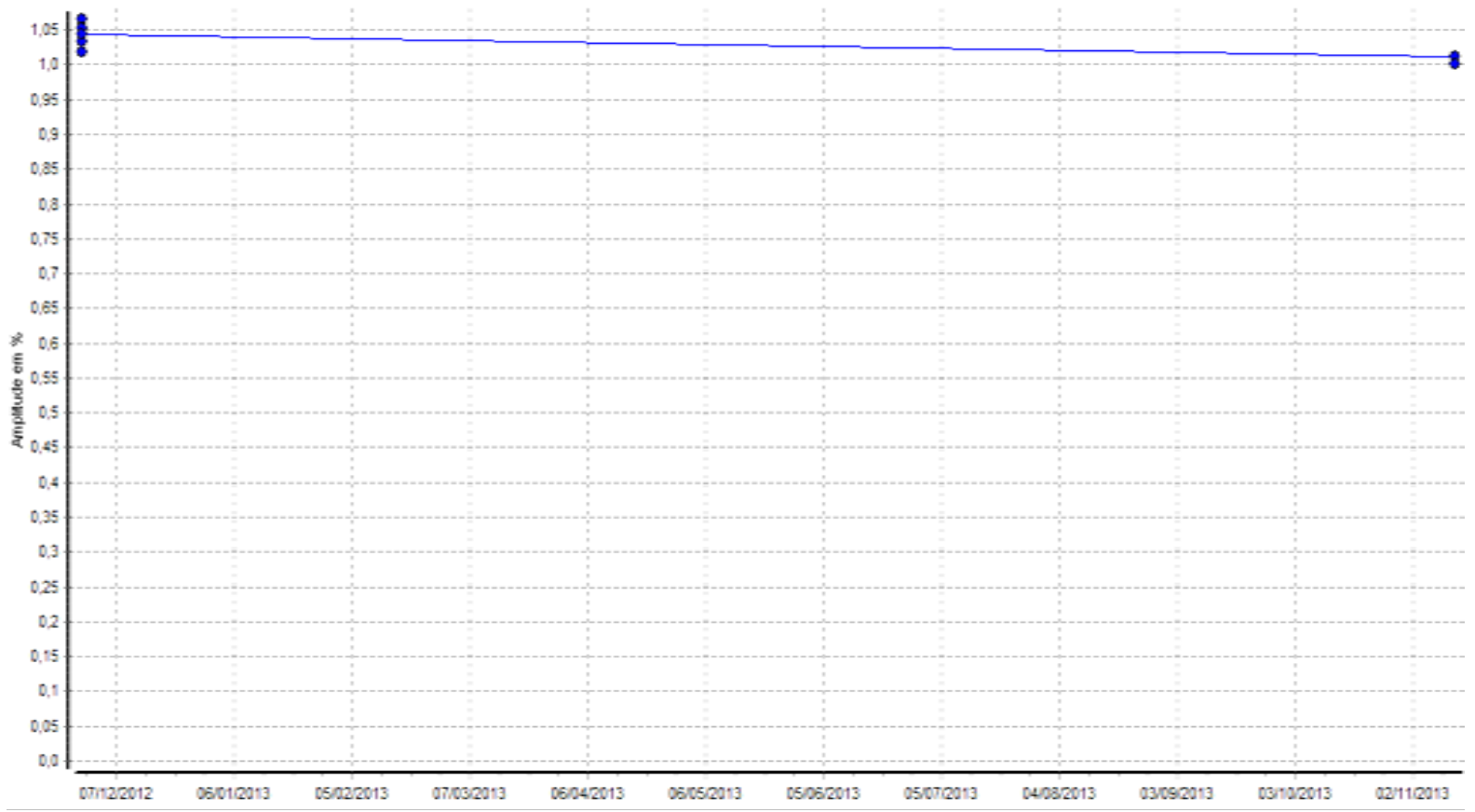

Figure 13. Voltage THD for phase C of unit \#2. 
and there is the prominence of a specific component. Another pattern for this failure is the monitoring of even harmonics in the signatures of current and voltage, as shown in Figure 15.

Another pattern is to follow the zero sequence harmonic current signature, correlating the signing of tension. Figure 16 highlights the harmonics of zero sequence current and voltage, with patterns which were identified. The pattern presented to a mechanical failure in the stator is the monitoring of the center frequency of the stator, given by $C F=R_{e} * f_{r}$ with sidebands on the frequency of generation. Figure 17 highlights these components in

Analise CSA eVISA
Aquisigäo. 1211173 1303:16
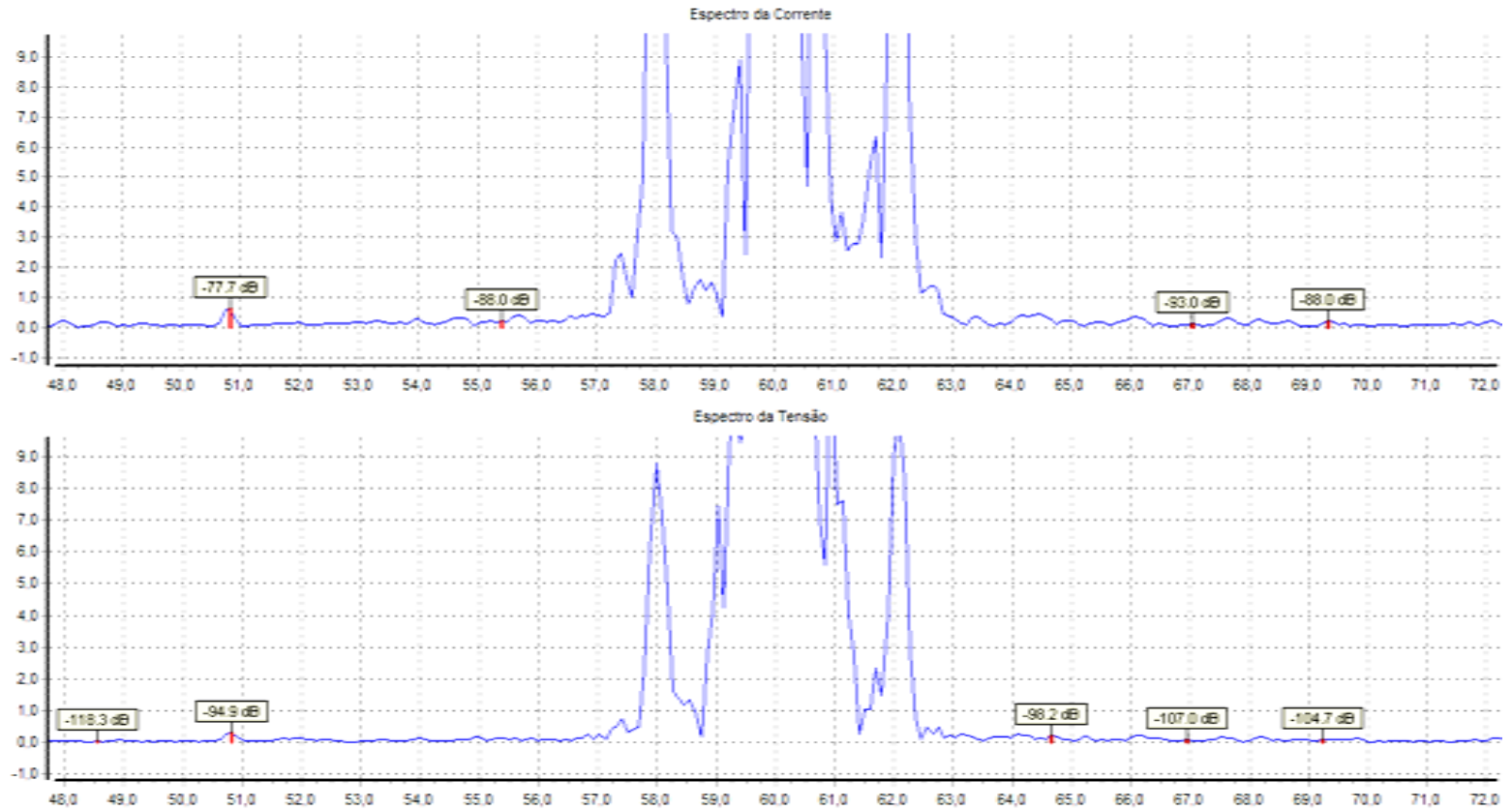

Figure 14. Rotation frequency patterns for unit \#2.

Análise CSA eVSA

Aquisigåa: 1211113 13:03:16

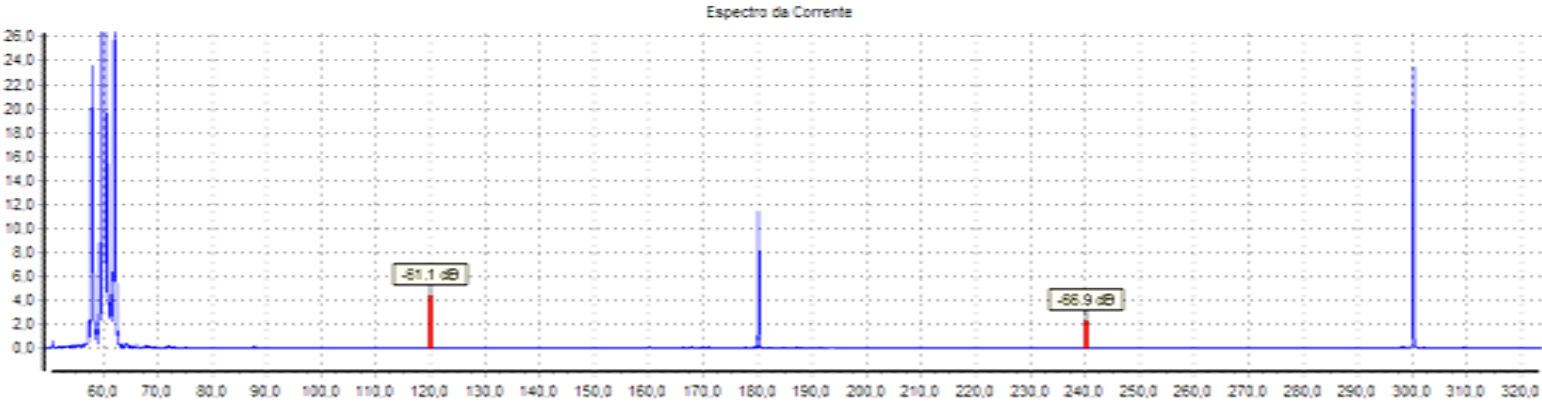
Essecro da Tensio

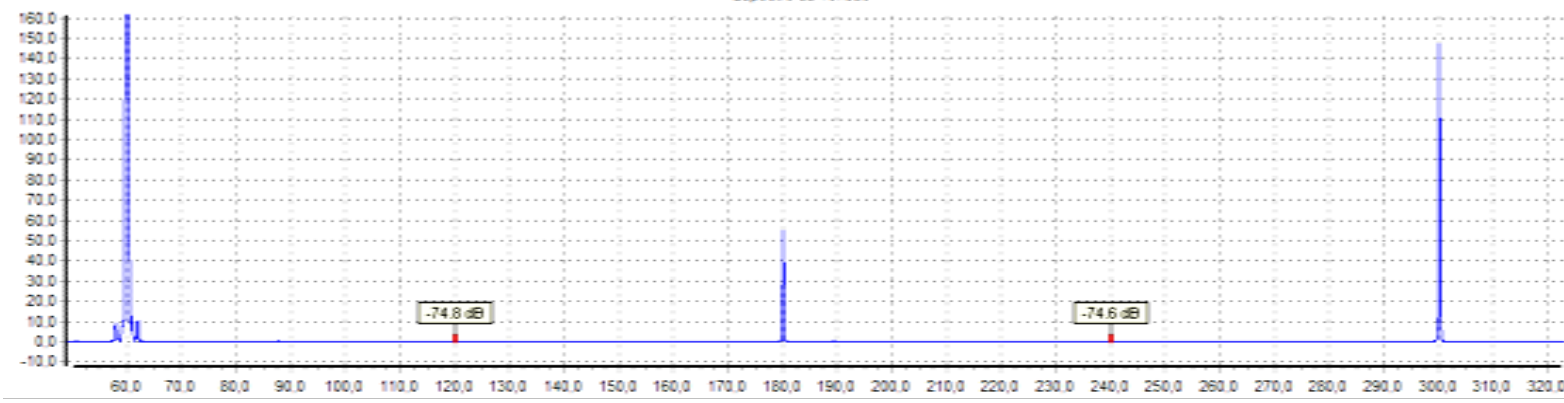

Figure 15. Even harmonic current and voltage patterns for unit \#2. 
Aralise CSA eVSA

Aquisigäo: 12211713 1800:15
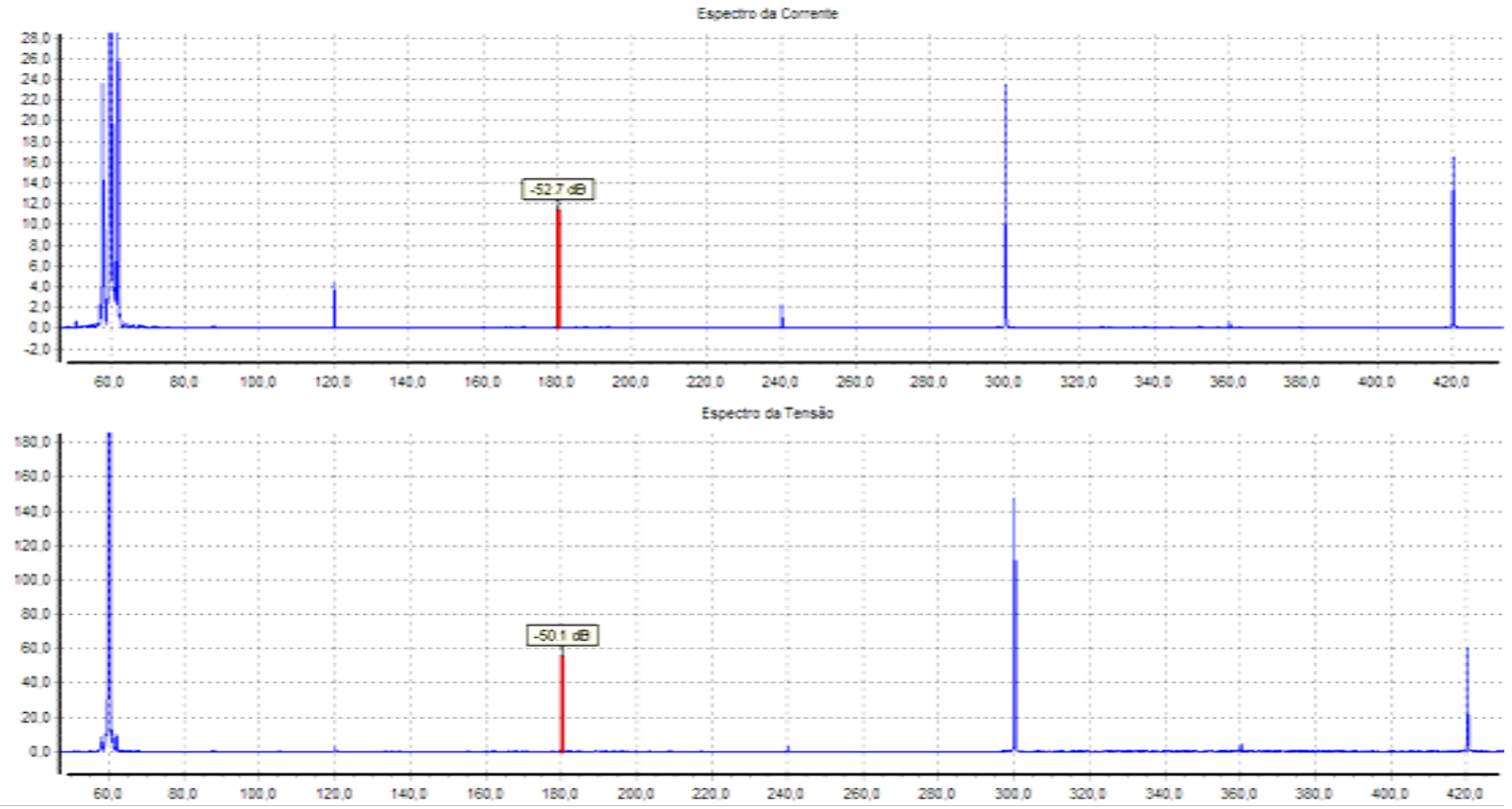

Figure 16. Zero harmonic current and voltage patterns for unit \#2.

Analise CSA eVISA

Aquisigão: $121111318: 03: 1$
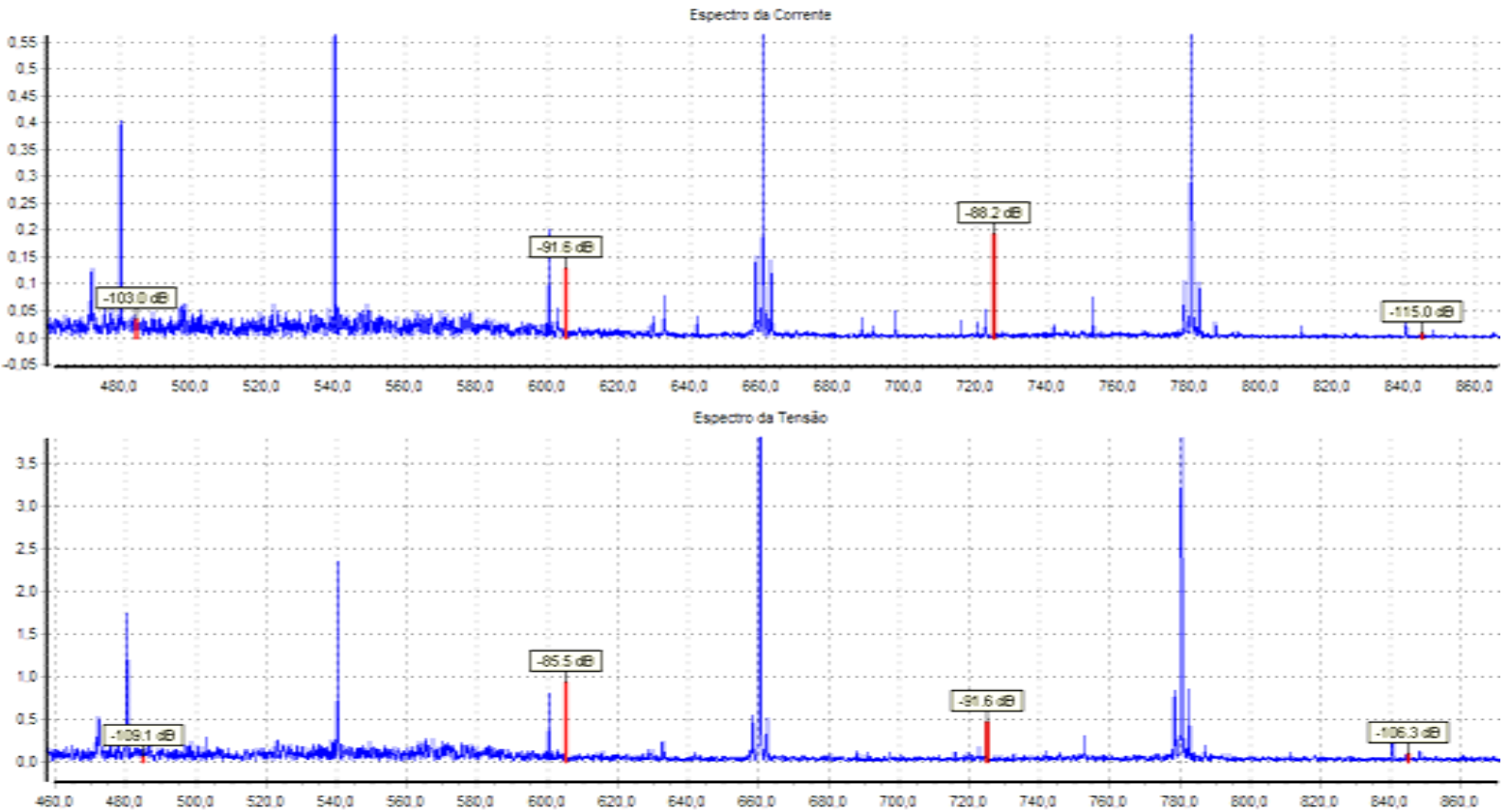

Figure 17. CSA and VSA analyses for unit \#2.

the CSA and VSA analyses.

\section{Conclusions}

This paper presents an automatic system for hydro-power generator failure detection. This system collects the current and voltage signals from the generator and it is able to detect premature failures in the electric part of the 
generator and mechanical failures in the generator, coupling, turbine, and bearing.

This system is currently installed in three 150 MW generating units at Itapebi Power Plant, in Southeast of Brazil. This online system can be programmed to monitoring the generating units automatically, and it also provides a set of alarms, which can be set by the users.

\section{Acknowledgements}

The authors would like to thank CNPq, CAPES, and ANEEL R\&D for support this project.

\section{References}

[1] Farag, W.A., Quintana, V.H. and Lambert-Torres, G. (1988) A Genetic-Based Neuro-Fuzzy Approach for Modeling and Control of Dynamical Systems. IEEE Transactions on Neural Networks, 9, 756-767. http://dx.doi.org/10.1109/72.712150

[2] Bonaldi, E.L., de Oliveira, L.E.L., Borges da Silva, J.G., Lambert-Torres, G. and Borges da Silva, L.E. (2012) Predictive Maintenance by Electrical Signature Analysis to Induction Motors. In: R. Araujo, Ed., Induction Motor -Modelling and Control, InTech, Croacia, 487-520.

[3] da Silva, C.H., Pereira, R.R., Borges da Silva, L.E., Lambert-Torres, G. and Pinto, J.O.P. (2011) New Strategies for Application of Adaptive Filters in Active Power Filters. IEEE Transactions on Industry Applications, 47, 1136-1141. http://dx.doi.org/10.1109/TIA.2011.2125931

[4] Borges da Silva, L.E., de Oliveira, L.E.L., Lambert-Torres, G., da Silva, V.F., P Pinto, J.O. and Bose, B.K. (2002) Improving the Dynamic Response of Active Power Filters Based on the Synchronous Reference Frame Method. Proceedings of Applied Power Electronics Conference, 2, 742-748. 